\title{
O que diz a literatura Brasileira em relação ao Currículo de Química
}

\section{What the Brazilian literature says about the Chemistry Curriculum}

\author{
Nycollas Stefanello Vianna (nycollasv@ hotmail.com) \\ Universidade Federal do Rio Grande (FURG) \\ Jaqueline Ritter (jaquerp2@gmail.com) \\ Universidade Federal do Rio Grande (FURG)
}

\begin{abstract}
Resumo:Apresenta-se resultados de estudo da arte que "identificar o que se entende como currículo de química na Educação Básica, concepções e práticas". Trata-se de resultados Quantitativos e Qualitativos de informações da referida área, quais sejam, anais de eventos e Portal de Periódicos da CAPES. Fez-se uso da Análise Textual Discursiva (ATD) que permitiu a produção de quatro categorias emergentes: Organização Curricular; Metodologias de Ensino; Ciência, Tecnologia e Sociedade CTS; e, História Curricular. Reconheceram-se entre os pesquisadores em ensino de Química, proposições alternativas às abordagens tradicionais de ensino, considerando que é imprescindível conhecer a história do currículo como uma construção cultural. Contudo, percebeu-se que os pressupostos teóricos sobre o currículo estão sendo mais debatidos que as práticas pautadas em tais pressupostos.
\end{abstract}

Palavras-chaves: CTS; História do currículo; Organização Curricular.

Abstract: It presents results of art study that "identify what is understood as a chemistry curriculum in Basic Education, conceptions and practices". These are Quantitative and Qualitative results of information of said area, that is, annals of events and Portal of Periodicals of CAPES. We used the Discursive Textual Analysis (DTA) that allowed the production of four emerging categories: Curricular Organization; Teaching Methodologies; Science, Technology and Society - STS; and, Curricular History. It was recognized among the researchers in Chemistry teaching, alternative propositions to the traditional approaches of teaching, considering that it is imperative to know the history of the curriculum as a cultural construction. However, it has been realized that theoretical assumptions about curriculum are being more debated than practices based on such assumptions.

Key Words: STS, Curriculum history; Curriculum Organization.

\section{INTRODUÇÃO}

Pesquisadores da área do Ensino de Química, no Brasil, têm dedicado suas pesquisas ao "currículo de Química", prezando pelos princípios da interdisciplinaridade e contextualização. Nesse trabalho, apresenta-se uma breve revisão de literatura das publicações realizadas nos últimos anos em algumas fontes de informações da área, em que se buscou conhecer a quantidade de trabalhos preocupados com este tema, bem como, as concepções e práticas que permeiam o conteúdo dos mesmos.

Essa revisão de literatura é parte de uma pesquisa de Mestrado que vem sendo desenvolvida no Programa de Pós-Graduação em Educação em Ciências, de uma 
Universidade Gaúcha, que busca identificar o que se entende como currículo de química na Educação Básica, concepções e práticas.

Nessa pesquisa a pergunta central do estudo é: Quais são as tendências atuais das pesquisas sobre o Currículo de Química e que currículo de química os pesquisadores da área do Ensino de Química consideram relevante e sobre quais critérios assenta-se a sua escolha?

Perseguindo a resolução deste problema, segue-se apresentando as concepções teóricas acerca de currículo, e a seguir, busca-se através de algumas publicações da área do Ensino de Química compreender as concepções que os professores/pesquisadores trazem em seus estudos sobre isto.

\subsection{AFINAL, O QUE É CURRÍCULO? ALGUMAS CONCEPÇÕES TEÓRICAS SOBRE ESTE INSTRUMENTO!}

Quando se começa a trabalhar sobre esse documento, a primeira dúvida que emerge é: Afinal o que é um Currículo na Educação? Será que é um papel que apenas norteia os professores com uma lista de conceitos a serem trabalhados ao longo do bimestre/trimestre/semestre/ano escolar?

Lopes e Macedo (2011) partem da premissa que não é possível responder o que é o currículo, e ainda há de se considerar que em uma visão simplista há o entendimento que esse instrumento é apenas uma listagem de conteúdos que regem as salas de aulas das escolas. Grundy (1987) aponta que o currículo não deve ser entendido como um conceito de fácil definição, mas sim como uma construção cultural, e Sacristán (1995) diz que o currículo, supõe a concretização dos fins sociais e culturais, de socialização acerca dos quais se faz a instrumentalização concreta da escola como parte de um determinado sistema social. Ao entender-se o currículo como um construto social, considera-se que ele apresenta uma história sociocultural de construção e que precisa ser constantemente revisitada, interpretada e reconstruída. Para tal, faz-se pertinente reconhecer aspectos da história recente do currículo, para então interpretar o currículo de Química em ação nas escolas de Educação Básica.

Apesar do aumento da preocupação com o entendimento do conceito 'currículo' na educação brasileira, o termo ainda traz muita dificuldade de compreensão pelos sujeitos envolvidos no processo educacional, por ser um campo de pesquisa, relativamente novo, principalmente no Brasil. Silva (2009), faz uma retrospectiva histórica e apresenta que o currículo, como um objeto de estudo específico nas pesquisas em educação nos Estados Unidos, surgiu em meados dos anos vinte, contudo só veio a nomear-se como tal, mais tarde.

Hamilton (1992) diz que a primeira menção ao termo 'currículo' remete ao ano de 1633 na Universidade de Glasgow - Escócia, e nessa época referia-se ao curso integral seguido pelos estudantes. Lopes e Macedo (2011) consideram que nesse momento o termo não implicou no surgimento de um campo de estudos, mas, que já estava ligado com a organização escolar de determinado grupo de sujeitos, sendo essa uma característica presente até os dias atuais em um dos sentidos mais consolidados para o termo. Silva (2009) destaca que foi na década de 1920 que provavelmente o currículo aparece como um objeto específico de estudo em Universidades nos Estados Unidos. Isso ocorre concomitantemente com o processo de industrialização norteamericana e também, junto aos movimentos imigratórios, que fazem com que haja uma massificação escolar, sendo que esses fatos podem ser vistos no trabalho de Bobbit (1918). Em estudos recentes, Buss (2017) argumenta que o currículo já é notoriamente 
reconhecido e estudado e é o ramo da Educação que trata da organização e do funcionamento das instituições de ensino.

Destaca-se que a visão de Bobbit faz com que os alunos sejam vistos como um objeto fabricado pelas grandes empresas e indústrias, ou seja, percebe-se uma visão capitalista em que o aluno é o produto e o professor é o operador que vai produzi-lo. Avançando alguns anos, chega-se no período de 1960-1969, quando emergem estudos que colocavam em xeque o pensamento e a estrutura educacional tradicional (SILVA, 2009, p.29). Para Maria Aparecida da Silva (2006) nesse período o currículo passa a ser tratado como um sistema tecnológico de produção:

A crítica advinda dos movimentos sociais expressava a insatisfação com a escola seletiva e excludente, despreocupada com o processo de aprendizagem dos alunos e esvaziada de conteúdos com significados vitais. Os movimentos sociais articularam algumas experiências alternativas de currículo, que, embora não constituam objeto deste trabalho fazer o seu mapeamento, vale salientar a sua importância pelo que representaram historicamente a possibilidade de pensar e fazer uma escola diferente. (SILVA, 2006, p.4824)

Além de apresentar discussões sobre a origem do currículo como campo de conhecimento, Silva (2009) traz um rápido resumo acerca de grandes eventos históricos registrados na década de 1960 no Brasil, sendo que nessa década, não por coincidência, surgiram teorizações que confrontavam com o pensamento e a estrutura educacional tradicional daquela época. Ainda na Década de 60, Taba (1962) e Tyler (1969) restringiram o conceito de currículo à organização de conteúdos a serem ensinados, qualquer que seja a concepção de conhecimento, porém, Mello (2014) diz que essa visão é considerada tecnicista e por isso vem perdendo força nos últimos anos.

Na concepção de Mello (2014), o currículo é centrado no conhecimento histórico das ciências, que como tal é falível e por isso deve ser submetido a uma problematização. A nova ideia considera a apropriação sistemática do mesmo, necessária, mas, articulado às situações sociais e culturais que demandam o seu uso e a intervenção humana nesse contexto. Da mesma forma, diferentemente da concepção do currículo centrado no aluno, considera-se insuficiente à reconstrução desse conhecimento descomprometida com a intervenção na realidade (MELLO, 2014).

Para Sacristán (1995) o currículo deve ser entendido também como uma cultura real que emerge de uma série de processos, deve desenvolver competências básicas da formação do estudante independente dos temas escolhidos. Quando se debate sobre o currículo das disciplinas de Química, é preciso buscar que o estudante "pelo menos entenda como o Químico pensa, numa tentativa de entender o mundo material em termos de átomos e moléculas e seus arranjos e movimentos" (FILHO, 2000, p.699). Espera-se que a disciplina de química, instituída no currículo da Educação básica, seja um meio pelo qual o estudante possa criar/formar um pensamento químico sobre o mundo. Sendo assim, considera-se importante reconhecer o que pensa e concebe a comunidade de Educação Química sobre o que de fato constitui o currículo de química.

\section{METODOLOGIA}

Para a realização da presente revisão de literatura utilizou-se como fonte de dados o Portal de Periódicos da Capes, bem como anais de dois importantes eventos para a área de Educação Química. Um a nível nacional, o Encontro Nacional de Ensino de Química (ENEQ) e outro a nível regional do Sul do Brasil, o Encontro de Debates sobre 
o Ensino de Química (EDEQ). As buscas estavam centradas em alguns termos no título, palavras-chave e resumo dos trabalhos. Na busca realizada no Portal de Periódico da Capes, adotou-se o sistema CAFe (Comunidade Acadêmica Federada), utilizando os dados de acesso cedidos pela Universidade na qual os pesquisadores são ligados. Adotaram-se, para a busca, os termos "currículo" AND "química", no período de 2013 a 2018. Ainda como forma de refinar a busca utilizou-se apenas periódicos revisados por pares, na língua portuguesa e com o tópico "education".

Para os trabalhos do ENEQ, um evento de âmbito Nacional, utilizaram-se os anais das últimas duas edições: 2012 e 2014. Os anais de 2016, não estavam disponíveis nos momentos das buscas deste estudo e a edição e 2018 ainda não havia ocorrido.

Já o EDEQ, por ser um evento que ocorre anualmente no Rio Grande do Sul, assim, a busca se deu pelos trabalhos dos anais dos últimos 4 anos, ou seja, anais da $34^{\text {a }}$ edição (2014), 35 (2015) e 36 ${ }^{\mathrm{a}}$ (2016)..

A análise inicial deteve-se no teor quantitativo de publicações e em seguida partiu-se para uma análise qualitativa. De acordo com Fonseca (2002), os resultados da pesquisa quantitativa são representativos, por expressarem um número elevado de publicações voltadas ao currículo de química. Em seguida, de forma qualitativa procedeu-se com a Análise Textual Discursiva (ATD), de Moraes e Galiazzi (2011), que se propõe "a descrever e interpretar alguns dos sentidos que a leitura de um conjunto de texto pode suscitar" (p.14). Salienta-se que adotar a ATD é assumir atitude fenomenológica, ou seja, deixar que os fenômenos se manifestem.

Optou-se pelo currículo de Química do Ensino Médio, pois, de acordo com a organização curricular da Educação Brasileira é nessa modalidade de ensino que se apresenta a Química, como disciplina escolar. Na leitura cuidadosa de cada trabalho, o primeiro momento da análise, consistiu em encontrar unidades de significado (US), que dialogassem com concepções e práticas enunciados pelos pesquisadores e professores sobre o currículo de química, razão pela qual Moraes e Galiazzi (2011) denominam de "desmontagem" dos textos. Para Moraes (1999), este é o processo de unitarização e compreende três momentos: fragmentações e codificações de cada unidade; após, a nucleação dessas US que levam a produção de categorias, e, por fim, a reescrita de cada US passa a assumir um significado mais completo no confronto com o referencial teórico a fim de produzir metatextos para cada categoria.

Os trabalhos analisados de acordo com os termos de busca foram assim identificados.

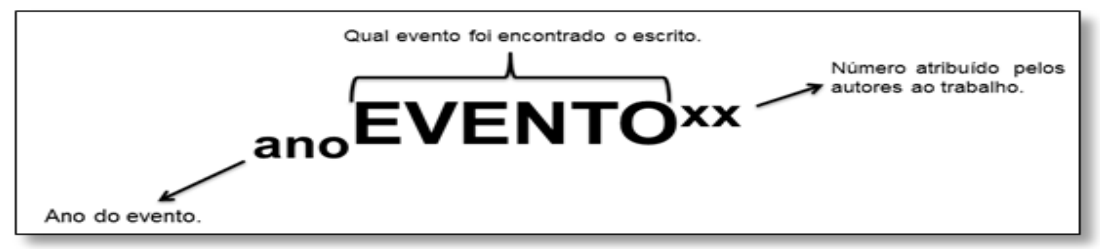

Figura 1: Código dos trabalhos com unidades de significados.

Os trabalhos encontrados no Portal de Periódico da Capes não possuem ao ano da publicação, visto que compreende um período determinado: De janeiro de 2013 a janeiro de 2018.

Os trabalhos analisados foram selecionados por meio de uma busca do termo "currículo" em seus títulos, resumos ou palavras-chaves. Foram selecionados e lidos todos os trabalhos que continham este termo e foram analisados posteriormente, os 
trabalhos com foco no Ensino Médio, momento em que a Química se consolida como componente curricular na educação básica brasileira.

As US de análise relevantes para esta pesquisa são as que ajudam na resolução do problema de pesquisa apresentado na introdução deste escopo. Segue-se com a apresentação dos resultados Quantitativos e Qualitativos deste estudo.

\section{RESULTADOS E DISCUSÕES}

\subsection{Análise Quantitativa ${ }^{1}$}

No Portal de Periódicos da Capes estão dispostos apenas artigos completos. Porém, na figura 2 apresenta-se o número de publicações encontradas em cada evento, com especificação de trabalhos completos e resumos:

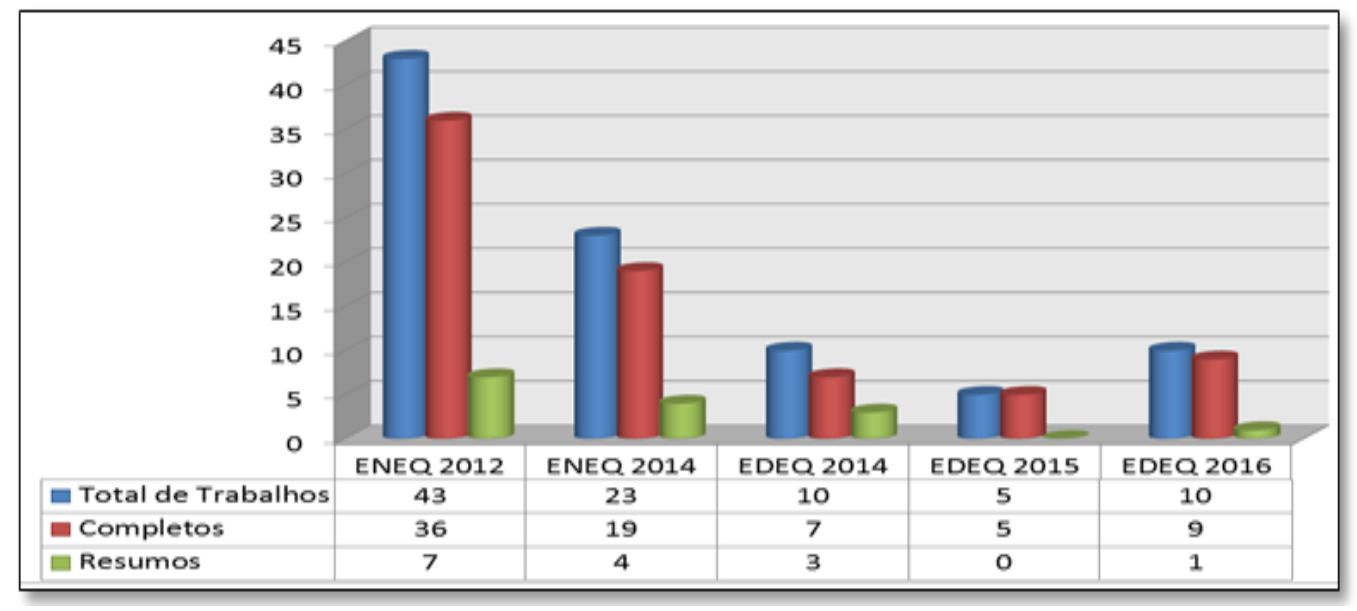

Figura 2: Gráfico do total de trabalhos encontrados nos anais de eventos.

Percebe-se, o expressivo número de trabalhos, sobre a temática, nos ENEQ, por se tratar de um evento no âmbito Nacional e apresentar um eixo de trabalhos com publicações voltadas ao currículo e avaliação no Ensino de Química. No EDEQ, o número de publicações preocupadas com o currículo de química, é menor e se mantém constante. Da mesma forma que nos anais do ENEQ (2012 e 2014), nos anais do EDEQ 2014, 2015 e 2016 fez-se a busca pelo termo "currículo" nos títulos, palavras-chave e resumos dos trabalhos. Apesar do número expressivo de trabalhos selecionados na primeira busca, poucos foram os que de fato continham unidades de significados capazes de responder ao problema central da pesquisa.

Depois dos refinamentos, obteve-se um total de 17 trabalhos que apresentaram unidades de significados para análise, segundo a ATD, com aproximações as intenções desta pesquisa. Na tabela 1, a seguir, têm-se as publicações que apresentaram US representativas de concepções e práticas para o currículo de Química, na Educação Básica.

1 Dados apresentados de forma resumida no II EREC - Encontro Regional de Ensino de Ciências, Maio de 2018. 
Tabela 1: Trabalhos que apresentaram US para a pesquisa.

\begin{tabular}{|c|c|c|}
\hline Código & Título & Autores \\
\hline${ }_{2012} \mathrm{ENEQ}^{01}$ & $\begin{array}{l}\text { Ensino de Química para Jovens e Adultos: contribuições curriculares a partir da } \\
\text { elaboração e implementação de uma proposta didático-pedagógica envolvendo temas } \\
\text { vivenciais. }\end{array}$ & $\begin{array}{l}\text { Lorenna Silva Oliveira Costa, Agustina Rosa } \\
\text { Echeverría. }\end{array}$ \\
\hline $2012 \mathrm{ENEQ}^{02}$ & $\begin{array}{l}\text { A concepção dos professores de química sobre o currículo no ensino médio noturno na } \\
\text { cidade de Jequié-Bahia }\end{array}$ & $\begin{array}{l}\text { Geovânia dos S. Moreira Souza, Bruno Ferreira } \\
\text { dos Santos. }\end{array}$ \\
\hline${ }_{2012} \mathrm{ENEQ}^{03}$ & Conflitos Temporais em uma proposta Curricular alternativa para o ensino de Química. & $\begin{array}{l}\text { Siméia dos Santos Cerqueira, Bruno Ferreira } \\
\text { dos Santos. }\end{array}$ \\
\hline $2012 \mathrm{ENEQ}^{04}$ & Construindo um módulo de ensino utilizando o tema: Nutrição para a promoção da saúde. & $\begin{array}{l}\text { Adriana Zechlinski Gusmão; Roberto Ribeiro da } \\
\text { Silva; Wagner Fontes. }\end{array}$ \\
\hline $2012 \mathrm{ENEQ}^{05}$ & A Bioquímica do amor: o que está por trás de um beijo? & $\begin{array}{l}\text { Éverton da Paz Santos, Gezyel Barbosa de } \\
\text { Aquino, Joyce de Souza Ferreira, Lenalda Dias } \\
\text { dos Santos, Maria Clara Pinto Cruz. }\end{array}$ \\
\hline${ }_{2012} \mathrm{ENEQ}^{06}$ & O Leite como tema motivacional para o ensino de Biomoléculas sob um enfoque CTSA. & Marcos Antonio Pessôa Leite. \\
\hline${ }_{2014} \mathrm{ENEQ}^{01}$ & $\begin{array}{l}\text { Aspectos socioculturais do currículo na educação básica: o "mundo da escola" na } \\
\text { significação do "mundo da vida". }\end{array}$ & $\begin{array}{l}\text { Laís Basso Costa-Beber, Jaqueline Ritter, } \\
\text { Otávio Maldaner. }\end{array}$ \\
\hline${ }_{2014} \mathrm{ENEQ}^{02}$ & $\begin{array}{l}\text { Ensino de Ciências da Natureza na realidade do Ensino Médio Politécnico: novo } \\
\text { currículo, novos olhares. }\end{array}$ & Bruna Carminatti, José Claudio Del Pino. \\
\hline $2014 \mathrm{EDEQ}^{01}$ & $\begin{array}{l}\text { Produção e Reciclagem do Papel: desenvolvendo } \\
\text { propostas curriculares diferenciadas numa abordagem CTS. }\end{array}$ & $\begin{array}{l}\text { Cássio Henrique Henn, Eunice Beatris Soares } \\
\text { Martins, Simone Soares. }\end{array}$ \\
\hline${ }_{2014} \mathrm{EDEQ}^{02}$ & $\begin{array}{l}\text { Atuação da Química em um projeto interdisciplinar no âmbito do PIBID Ciências e } \\
\text { Matemática. }\end{array}$ & $\begin{array}{l}\text { Michele Dubow, Joélcio Rosa da Silva Júnior, } \\
\text { Maira Ferreira. }\end{array}$ \\
\hline $2015 \mathrm{EDEQ}^{01}$ & A utilização da Temática "Esporte" sob uma perspectiva CTS. & $\begin{array}{l}\text { Thaís Rios da Rocha, Mara Elisa Fortes } \\
\text { Braibante. }\end{array}$ \\
\hline${ }_{2016} \mathrm{EDEQ}^{01}$ & Autonomia na construção curricular: o professor em atividade de pesquisa. & $\begin{array}{l}\text { Laís dos Santos Tavares, Andréia Rosa de Avila } \\
\text { de Vasconcelos, Jaqueline Ritter. }\end{array}$ \\
\hline${ }_{2016} \mathrm{EDEQ}^{02}$ & Ensino de Química e Geografia: Práticas Pedagógicas Integradas. & $\begin{array}{l}\text { Denis da Silva Garcia, Emersom Ciocheta } \\
\text { Roballo. }\end{array}$ \\
\hline portalCAPES 01 & $\begin{array}{l}\text { Análise do discurso sobre o currículo presente em um referencial curricular oficial de } \\
\text { Química para o ensino médio em Goiás-Brasil. }\end{array}$ & $\begin{array}{l}\text { Ramon Marcelino Ribeiro Jr., Agustina Rosa } \\
\text { Echeverría. }\end{array}$ \\
\hline $\begin{array}{l}\text { portalCAPES } \\
\text { Espanhol }\end{array}$ & $\begin{array}{l}\text { Caracterización de los contenidos curriculares contextualizados para la enseñanza de la } \\
\text { química. }\end{array}$ & Yaneth Piñeros, Diana Parga. \\
\hline $\begin{array}{l}\text { portalCAPES } \\
\text { Espanhol }\end{array}$ & $\begin{array}{l}\text { Analisis de los diseños y contenidos curriculares para la enseñanza de la química en las } \\
\text { instituciones de educación media en relación con las modalidades acadêmicas. }\end{array}$ & $\begin{array}{l}\text { Fredy Alberto Peralta Burgos, Diana Lineth } \\
\text { Parga. }\end{array}$ \\
\hline $\begin{array}{l}\text { portalCAPES } \\
\text { Espanhol }\end{array}$ & Dificultades de enseñanza-aprendizaje y su relación con las actitudes hacia la química. & Mónica Ipuz, Diana Parga. \\
\hline
\end{tabular}

Nesta amostra de 17 trabalhos, foram reconhecidas 35 US, que foram agrupadas em 4 categorias: História do currículo, Organização Curricular, Metodologias de Ensino e Ciência, Tecnologia e Sociedade (CTS), apresentados conforme segue.

\subsection{Análise Qualitativa}

Uma das características da ATD de Moraes e Galiazzi (2011) é a elaboração e organização de Categorias, que possuem elementos de definição e interpretação e que são apresentados em discutidos na forma de metatextos os quais expressam uma compreensão aprofundada do texto-base do corpus. Ainda é importante destacar, que as categorias não se encontram prontas nos textos analisados, e que construí-las exige um 
esforço construtivo e rigoroso por parte do pesquisador. As categorias que seguem, permitem explicitar o que vem sendo publicado na área sobre o tema "currículo".

\title{
3.2.1. A Primeira Categoria: Metodologias de Ensino ${ }^{2}$
}

Muitas pesquisas voltadas ao currículo de Química têm buscado alternativas para contrapor-se ao currículo tradicional, e para isso acabam propondo novas metodologias para que o currículo seja organizado de uma maneira mais dinâmica e assim, se torne mais significativo ao educando, no processo de ensino-aprendizagem. Delizoicov (1990) defende que o trabalho do professor deve ser direcionado para uma apropriação crítica, para que efetivamente, os fenômenos se incorporem no universo das representações sociais e se constitua como cultura para os estudantes.

Uma das metodologias proposta na constituição desse novo currículo é a sua articulação com os temas vivenciais, capazes de articular-se ao cotidiano dos educandos.

\begin{abstract}
Elaboramos e implementamos uma proposta didático-pedagógica estruturada em temas vivenciais, em específico "A química dos Alimentos" (2012 $\mathrm{ENEQ}^{01}$ - grifos nossos)
\end{abstract}

Nosso intuito, ao propor uma abordagem dos conteúdos por temas vivenciais, não é sobrevalorizar ou igualar o conhecimento cotidiano ao conhecimento científico. (2012 $\left.\mathrm{ENEQ}^{01}\right)$

A utilização de temas regionais no ensino de Química como um meio de educação para a vida, relacionando os conteúdos aprendidos com o cotidiano dos alunos, pode auxiliar muito o processo de ensino-aprendizagem de conceitos químicos. Por esse motivo o uso do leite como tema motivacional é uma possibilidade de ensino-aprendizagem que pode relacionar ciência, tecnologia, sociedade e ambiente, enfoque (CTSA), visando uma aprendizagem significativa. (2012 $\mathrm{ENEQ}^{06}$ - grifos nosso)

Percebe-se nas US, as intenções que movem os professores na direção dos temas vivenciais, qual seja aproximar conhecimentos científicos de cotidianos, a exemplo da "química dos alimentos" ou "o uso do leite". A abordagem curricular por temas tem sido então uma aposta, conforme a US, que segue, argumenta-se;

Assim, o mundo da vida e o mundo da escola se entrelaçam, de maneira que um possibilita com que o outro faça mais sentido. Tal postura pode ter como consequência uma seleção ou reorganização dos conhecimentos científicos que fazem parte da tradicional cultura curricular, validada historicamente. $\left(2014 \mathrm{ENEQ}^{01}-\right.$ grifo nosso)

Para alguns pesquisadores, é necessário buscar uma aproximação do mundo científico com o mundo social que extrapola o mundo da escola, sendo que dessa forma os conceitos teóricos e científicos possam a gerar mais significado ao aluno, visto que ainda percebe-se nas escolas um ensino livresco e pouco contextualizado.

Para tal mudança é necessário haver uma reorganização do currículo tradicional baseado em uma sequência pré-determinada de conteúdos teóricos e apostar-se em uma nova forma de abordar a química, em um momento em que os conceitos vão emergindo

2 As categorias "Metodologia de Ensino" e "Ciência, tecnologia e Sociedade - CTS" foram apresentadas previamente no XIX ENEQ - Encontro Nacional de Ensino de Química, Julho de 2018. 
com o avançar do estudo, a exemplo do que ocorre com a produção de "situações de estudo".

No desenvolvimento das Situações de Estudo em contexto escolar, busca-se atribuir sentidos e significados aos conceitos necessários para o entendimento de situações reais pertencentes ao mundo da vida dos estudantes. (2014ENEQ ${ }^{01}$ - grifo nosso)

Entende-se que a contextualização dos conceitos científicos no cotidiano no qual o estudante está inserido, requer um pouco mais do trabalho docente, porém, existe uma maior possibilidade de obter-se resultado satisfatório em termos de aprendizagem. Os PCN (BRASIL, 2002) da Educação brasileira orientam os professores a repensar o ensino e a organização do currículo nas escolas brasileiras, para que o foco passe a ser a construção do conhecimento por parte do aluno e o desenvolvimento de competências necessárias para que ele seja capaz de intervir e de entender a realidade. Para que isso ocorra, há a sugestão de um ensino contextualizado e assim uma das possibilidades de alcançar-se esse objetivo, sugere-se a organização do currículo por Abordagens Temáticas (DELIZOICOV, ANGOTTI e PERNAMBUCO, 2002). Estes autores entendem a Abordagem temática como a:

\begin{abstract}
Perspectiva curricular cuja lógica de organização é estruturada com base em temas, com os quais são selecionados os conteúdos de ensino das disciplinas. Nessa abordagem, a conceituação científica da programação é subordinada ao tema. (DELIZOICOV, ANGOTTI e PERNAMBUCO, 2002; p. 189)
\end{abstract}

Sendo assim, esta abordagem parte da utilização de temas de relevância social em sala de aula fazendo a sua correlação com os conteúdos programáticos e com os temas abordados. Assim, o estudante é conduzido a um pensamento conceitual contextualizado se torna o ator ativo do processo de ensino-aprendizagem;

El docente es quien conoce la verdadera distancia entre la ciencia erudita y la
ciencia escolar y es el responsable directo en la construcción y significación
de un nuevo conocimiento científico (...) es necesario conocer y aplicar la
didáctica en cada uno de los contenidos seleccionados, es necesario
identificar los intereses y necesidades de sus estudiantes...
(portal CAPES $^{03(\text { (espanhol) }}$ - grifo nosso)

Percebe-se na US a preocupação do docente em realizar a transposição didática que de acordo com Menezes e Santos (2018) é uma forma de transformar o conhecimento científico em conhecimento escolar. Chevallard (1991) aponta que:

Um conteúdo de saber que tenha sido definido como saber a ensinar, sofre, a partir de então, um conjunto de transformações adaptativas que irão torná-lo apto a ocupar um lugar entre os objetos de ensino. O 'trabalho' que faz de um objeto de saber a ensinar, um objeto de ensino, é chamado de transposição didática (CHEVALLARD, 1991, p.39).

Para atuar em sala de aula, o professor precisa entender a diferença entre o saber científico (aquele que está presente nas instituições de pesquisas, universidades) e o conhecimento a ser ensinado (aquele presente nos PCN, nos Livros Didáticos, no currículo em ação), sendo que a partir da transposição didática há uma democratização do conhecimento, a qual muda sua natureza epistemológica. Essa passagem do saber científico para saber didático é um exercício de selecionar e relacionar o conhecimento acadêmico científico adequando às possibilidades cognitivas dos educandos $\mathrm{e}$ contemplá-los à luz do universo social e cultural desses educandos e, não apenas servir 
de meio de exemplificação. Este é sem dúvida o sentido da transposição didática e que precisa ser compreendido pelos professores e que os documentos oficiais pós-LDB no Brasil (BRASIL, 1998) e a literatura brasileira, tentaram inserir pelo princípio da contextualização e interdisciplinaridade a fim de produzir argumentos e compreensões.

[...] es necesario la reestructuración del currículo en el que se tenga en cuenta el desarrollo de las temáticas a partir de conceptos estructurantes o centrales, que permitan cambiar la visión de una química en la que se trabajan temáticas desarticuladas con lenguajes difíciles y que a través de la construcción de tramas didácticas, se pueda aportar a mejorar parte de las dificultades presentes; (portal CAPES $^{04(\text { espanhol) }}$ - grifos nossos)

Buscar uma alternativa ao currículo tradicional é necessário para que exista uma apropriação do pensamento químico pelos estudantes, para que o ensino de conceitos químicos, de forma isolada, abstrata e descontextualizada seja revisto e reestruturado. Para isso, há argumentos a favor de abordagens temáticas, expressas como temas vivenciais e situações de estudo. Contudo, entende-se que a forma como tais temas são trabalhos pode evidenciar apenas uma mudança de metodologia e não necessariamente uma concepção de currículo. Acredita-se que esse debate não se encerra no curso dessa categoria ou deste trabalho, uma vez que é preciso explicitar melhor quais metodologias se mostram mais evidentes em uma ou outra concepção de currículo, para que assim seja possível alcançarmos melhores resultados de aprendizagens nos componentes curriculares de Química nas escolas públicas Brasileiras.

\subsubsection{A Segunda Categoria: Ciência, Tecnologia e Sociedade - CTS.}

Abordagens de enfoque CTS vêm ganhando cada vez mais espaço nas publicações da América Latina (SANTOS e AULER, 2011), pois trata-se de uma linha de pesquisa emergente e que apresenta como proposta de currículo a associação entre os três campos: A Ciência, a Tecnologia e a Sociedade. Para Santos (2011) o movimento CTS tomou forma nas últimas décadas, e os dados revelam que ele permanece ativo. Para o autor, desde o século XIX há uma discussão sobre a necessidade de a educação científica voltar-se para um público geral. Assim, o movimento CTS acaba contribuindo para que a educação científica se consolide no propósito de formação para a cidadania e, também tornar-se um caminho ou meio para a recontextualização dos conhecimentos científicos escolares, conforme discutido anteriormente.

$\mathrm{Da}$ mesma forma que na categoria anterior, é recorrente a preocupação dos professores-pesquisadores, em buscar um currículo próximo do cotidiano do aluno, produzindo novos significados, interpretações, decisões, etc. Por meio dessa concepção, se aposta na melhora da qualidade do processo de ensino e de aprendizagem.

O presente trabalho destaca o movimento CTS e sua importância na realização de um currículo de ciências que utilize temas sócio-científicos. Este tipo de abordagem visa o desenvolvimento de habilidades e competências nos estudantes, estimulando o pensamento crítico e a tomada de decisões. (2015EDEQ $\mathrm{EQ}^{01}$ - grifos nossos)

O principal objetivo para a inserção de temas CTS no currículo de Ciências e a efetiva inter-relação entre os conhecimentos científicos e tecnológicos $\left({ }_{2015} \mathrm{EDEQ}^{01}\right)$

Santos (2011) afirma que nos anos 70, no Brasil, o movimento CTS começou a se preocupar com formação para a cidadania. O foco não era, apenas, que o educando concluísse seus estudos, mas, além disso, que se encontrasse como cidadão no mundo. Para isso, o movimento CTS tem colaborado para que a educação científica se consolide no propósito da formação para a cidadania. Assim "o movimento CTS no Ensino de Ciências contribuiu para a inserção de temas sociocientíficos, como engajamento em 
ações sociais responsáveis, questões controversas de ética e problemas ambientais contemporâneos" (SANTOS, 2011, p.23). Os temas sociocientíficos, também alinhamse as perspectivas de abordagens temáticas e contemplam a perspectiva epistemológica da aproximação entre os conhecimentos científicos e os temas sociais cotidianos, com a ressalva de que alguns são de natureza controversa e outros, não.

Assim, quando se pensa no movimento CTS, é preciso compreender que um currículo centrado nesse enfoque além de associar conceitos científicos ao cotidiano dos estudantes, tem a preocupação em formar um cidadão crítico, capaz de ter pleno pensamento químico sobre os fenômenos que o cercam no dia-a-dia e qualificar seu processo de tomada de decisão.

Nessa perspectiva, tem se considerado que o ensino de Química deve estar relacionado à formação do cidadão, apresentando ao aluno uma concepção de Ciência como atividade humana em construção que leve em conta o papel social da Ciência. Diante disso, o ensino experimental tem sido utilizado como uma estratégia para promover a aprendizagem significativa no ensino de ciências $\left({ }_{2012} \mathrm{ENEQ}^{06}-\right.$ grifos nossos).

Pode-se perceber na US supracitada, que os autores apresentam a perspectiva CTS, também como alternativa para pensar as atividades experimentais da Química, como ciência comprometida com o meio ambiente, social e cultural. Barberá e Valdés (1996) dizem que a atividade experimental proporciona uma experiência direta e visível sobre os fenômenos, permite derrubar o paradigma de uma ciência abstrata, desenvolve nos alunos um raciocínio prático e, ainda, o familiariza com o instrumental científico.

Percebe-se nessa US, a preocupação com a formação do cidadão, algo já apontado nos documentos oficias que regem o Ensino Médio (BRASIL,2006), os quais defendem que a Química deve superar a memorização de fórmulas e nomes desconectados da realidade dos alunos. De acordo com Brasil (2006):

O aprendizado de Química no ensino médio “[...] deve possibilitar ao aluno a compreensão tanto dos processos químicos em si, quanto da construção de um conhecimento científico em estreita relação com as aplicações tecnológicas e suas implicações ambientais, sociais, políticas e econômicas". (BRASIL, 2006, p.87)

Diante de tal discussão e análise, salienta-se que os documentos oficiais também apontam que a seleção de conteúdos deve basear-se em temas relevantes que levem o educando a uma compreensão do mundo natural, social, político e econômico. Assim, percebe-se a importância da linha CTS nas pesquisas voltadas ao currículo, visto que contemplam discussões necessárias e pertinentes à construção de um currículo voltado a formação do cidadão. A US, que segue, vai nesta direção.

O último aspecto a ser destacado é a importância de se trabalhar a ciência e a tecnologia a partir de temas que possuam grande relevância social, mostrando ao aluno o papel significativo do mesmo na sociedade. (2015 $\mathrm{EDEQ}^{01}$ - grifo nosso).

Santos (1992) defende que a inclusão de temas sociais é recomendada, e vem sendo aceita e bem reconhecida na comunidade de Educação Química, pois evidenciam a inter-relação entre os aspectos científicos, tecnológicos e da sociedade e ainda propiciam condições para o desenvolvimento de atitudes e tomadas de decisões, as quais podem ser interpretadas como competências desenvolvidas a partir da linguagem científica significada e (re) significada em processos de ensino (RITTER, 2017). Igualmente, destaca-se que é necessário explicitar a compreensão do papel social da 
Educação em Ciências para que os currículos não sejam apenas a aplicação das ciências à sociedade (SANTOS E MORTIMER, 2000).

Santos (1992) ainda destaca que é necessária a adoção de temas envolvendo questões sociais relativos à ciência e à tecnologia que estejam ligados a vida dos alunos fora da escola e tais aspectos foram evidenciados nesta pesquisa. Mais uma vez, reiterase que concepções curriculares poderão orientar metodologias de ensino múltiplas, mas para isso, antes é preciso reconhecer com que ou qual enfoque teórico-metodológico de ensino e aprendizagem está-se orientando essas concepções e práticas curriculares.

\subsubsection{A Terceira Categoria: História do Currículo ${ }^{3}$}

O que é currículo? Qual a história deste instrumento? Essas são algumas perguntas que têm inquietado os pesquisadores da Educação, que têm dedicado suas pesquisas ao currículo. Relativo à primeira questão, poderemos encontrar na Literatura diversos autores defendendo uma determinada definição ao termo. Tanner (1975) entende que currículo: "é definido como as experiências de aprendizagens planejadas e guiadas e os resultados de aprendizagem não desejados formulados através da reconstrução sistemática do conhecimento e da experiência sob os auspícios da escola para o crescimento contínuo e deliberado à competência pessoal e social do aluno" (p.45). De outra parte, Silva (2009), em sua obra, reconhece que uma das primeiras publicações da área para entender o conceito de currículo parte do norte-americano Bobbitt no ano de 1918 que concentra as ideias de um grupo de pessoas ligadas à administração da educação, cuja ideia de currículo referia-se apenas a especificação precisa de objetivos para se alcançar resultados que pudessem ser mensurados.

A preocupação com o conhecimento sobre a história do currículo, está presente nas publicações, logo, nas US identificadas. Para essa categoria reuniu-se duas US de extrema importância, pois, debatem justamente sobre a necessidade de conhecer-se a história do currículo, como o resultado de uma construção histórica e evolutiva.

A análise das teorias tradicionais às críticas nos permite inferir que é preciso interpretar o currículo não como resultado de um processo evolutivo, que vai se aperfeiçoando com o decorrer do tempo, mas que nesse processo histórico há descontinuidades e rupturas. (2012 $\mathrm{ENEQ}^{01}$ - grifo nosso)

Além de apresentar discussões sobre a origem do currículo como campo de conhecimento, Silva (2009) traz um rápido resumo acerca de grandes eventos históricos registrados na década de 1960 no Brasil, sendo que nessa década, não por coincidência, surgiram teorizações que confrontavam com o pensamento e a estrutura educacional tradicional daquela época. Na Década de 60 restringiu-se o conceito de currículo à organização de conteúdos a serem ensinados, qualquer que seja a concepção de conhecimento, porém, de acordo com Mello (2014) essa visão é considerada tecnicista e por isso vem perdendo força nos últimos anos. A histórica do currículo reitera seu importante papel na formação social e cultural do estudante conforme aponta a seguinte US.

Entende-se por currículo o espaço em que se desenvolvem, nas escolas e salas de aula, as manifestações referentes ao conhecimento e experiências escolares, conhecimentos e experiências que têm o papel de relacionar questões que afetam integralmente a formação social do estudante. $\left(2012 \mathrm{ENEQ}^{02}\right)$

\footnotetext{
3 Recorte apresentado no III Congreso Internacional sobre Formación de Profesores de Ciencias, Outubro de 2018 - Bogotá - Colômbia.
} 
Assim, o currículo de Química deve, de acordo com os documentos oficias da Educação Básica Brasileira (BRASIL, 2006), "facilitar o desenvolvimento de competências e habilidades e enfatizar situações problemáticas reais de forma crítica, permitindo ao aluno desenvolver capacidades como interpretar e analisar dados, argumentar, tirar conclusões, avaliar e tomar decisões" (p.89), assim, auxiliando na formação de um cidadão crítico capaz de intervir na sua realidade.

Mota, Veloso e Barbosa (2004) concebem o currículo como uma ferramenta imprescindível para se compreender os interesses que atuam e estão em permanente jogo na escola e na sociedade e na visão dos autores, discutir o currículo é debater uma perspectiva de mundo, de sociedade e de ser humano. Assim, os temas sociais contemporâneos podem ser entendidos como partes do currículo e não apenas como conteúdos colocados de forma assistemática ou eventual, desvinculados $\mathrm{e}$ descomprometidos da vida e da comunidade.

\title{
3.2.4. A Quarta Categoria: Organização Curricular
}

O termo "currículo" ainda está ligado diretamente à organização curricular, e muitas das US identificadas apresentam propostas e ideias para se romper com um currículo estático, tradicional focado apenas no professor e na transmissão de conhecimento. Para Siqueira (2009) o currículo na perspectiva tradicional entende o conhecimento como algo estático e objetivo, e o professor cumpre o papel de transmitilo. Já o educando é visto como um receptor passivo desse conteúdo transformado em objetos de ensino. Na teoria tradicional, os objetos de ensino são os saberes privilegiados pelo contexto sociocultural da classe dominante, ignorando-se a cultura dos grupos minoritários na relação com tal objeto. Alguns trabalhos criticam esse currículo, pois, é necessário que o aluno conceba sentido nos conteúdos ensinados em sala de aula e que assim possa haver mobilização dos mesmos no seu cotidiano.

\begin{abstract}
Por isso há uma grande importância em recriar o currículo escolar de modo a romper com o modelo tradicional, fazendo com que o estudante não conheça apenas o conteúdo disciplinar que é importante segundo uma lógica academicista, mas que o reconheça inserido na sua realidade. (2016EDEQ ${ }^{01}-$ grifo nosso)
\end{abstract}

Assim, surgem algumas propostas de trabalho com a apresentação de novas metodologias para que exista uma flexibilização do currículo e uma aproximação maior à realidade dos estudantes. Como dito anteriormente, concepções de currículo associadas às interpretações epistemológicas acerca da natureza do conhecimento escolar evidenciam que ao pensar na metodologia de ensino, antes é preciso reconhecer que ensino escolar é esse. E também, como o adolescente em fase escolar aprende? Percebeu-se que tais relações ou associações envolvendo discussões curriculares, nos trabalhos analisados, quase na sua maioria, não vieram acompanhadas de reflexões epistemológicas e da psicologia da aprendizagem e desenvolvimento. Vê-se muito mais discussões sobre propostas de temas, abordagens com críticas ao famoso método tradicional de ensino.

Uma das propostas apresentadas é a abordagem de temáticas utilizando Unidades de Aprendizagens (UA) vista por Galiazzi, Garcia, Lindemann (2004) como uma proposta curricular flexível, alicerçada no diálogo e visando o afastamento da conhecida metodologia tradicional e sequencial apresentada nos livros didáticos. Algumas US defendem essa abordagem, preocupada em propor aos alunos, aulas mais interativas para que os mesmos concebam sentido nos conceitos científicos ensinados. 
Trazemos para o foco de nossa proposta a metodologia de "Unidades de Aprendizagem (UA)" como uma proposta de organização curricular flexível, alicerçada no dialogo e visando o afastamento da conhecida metodologia tradicional e sequencial apresentada nos livros didáticos. (2014EDEQ ${ }^{01}$ - grifo nosso)

As abordagens temáticas são apontadas como uma metodologia otimizadora do processo de aprendizagem, visto que integra conhecimentos cotidianos e/ou culturais além de conteúdos de outras disciplinas. Desse modo, não somente produzindo conhecimentos acerca de assuntos relacionados à Química, mas oferecendo um saber generalizado e interconectado. (2012 $\mathrm{ENEQ}^{05}$ - grifo nosso)

A proposta explicita a intenção de ensinar Química aos alunos com "outros conteúdos e de outras maneiras", a fim de desenvolver neles competências para aprender, bem como tornar os alunos mais críticos e criativos, com melhor autoestima, participantes da construção do conhecimento, e, consequentemente, "mais cidadãos". (2012 $\mathrm{ENEQ}^{03}$ - grifo nosso)

Percebemos nas US, uma preocupação em apresentar os conceitos científicos aos estudantes, porém, de forma diferenciada, buscando que o educando busque uma associação do conhecimento científico ensinado em sala de aula, com o seu cotidiano, com o argumento de que é preciso que o docente busque estratégias para desmistificar o conceito de que a química está afastada do cotidiano dos alunos.

Um dos grandes problemas do professor de Química é a grande desvinculação dos conteúdos da realidade dos alunos; além disso, a grande parte dos professores segue uma abordagem tradicional de ensino, baseada em aulas expositivas e metódicas, que torna o processo educacional bastante precário. (2012 $\mathrm{ENEQ}^{05}$ - grifo nosso)

O professor de química pode, através de novas metodologias e de uma interação entre a área de Ciências da Natureza (Química, Física e Biologia), conforme indica a Lei de Diretrizes e Bases da Educação Brasileira $n^{\circ}$ 9.394/96 (BRASIL, 1996), aproximar conceitos científicos do cotidiano do discente, buscando a melhora do ensino nas escolas públicas Brasileiras. Contudo, pouco se discute acerca de como se faz isso:

Portanto, através da pesquisa, busca-se compreender a chegada deste novo currículo sob a luz dos saberes docentes e da interdisciplinaridade, que são marcos fundamentais da educação brasileira, estando não só presentes na proposta em questão, mas também nas diretrizes e leis que regem a educação em nosso país. (2014ENEQ ${ }^{02}-$ grifos nossos)

Reconhece-se que várias US manifestam a intenção dos pesquisadores em apresentar sugestões de propostas metodológicas para um "novo" currículo, ou trouxeram argumentos para um ensino menos tradicional. Entretanto, tal discussão reitera a necessidade de que é preciso compreender que o currículo deve levar em consideração mais que métodos ou técnicas de ensino para uma determinada ciência. Os discursos produzidos em torno do argumento de que se deve respeitar o contexto sociocultural de ensino e o modo como a escola recebe uma nova geração de aprendizes ainda é pouco debatida/discutida. Dessa forma, ao revisitar o debate em torno da LDB (BRASIL, 1996), e o que recentemente se propõe como Base Nacional Curricular Comum (BNCC) vê-se que novos argumentos estão sendo produzidos, mas que não entraram diretamente nesta análise.

$\mathrm{O}$ quanto às políticas curriculares são capazes de nortear ou orientar as concepções de currículo em curso não foi objeto desse estudo, muito embora tenham sido citadas ou referidas como argumento às abordagens temáticas. Este é sem dúvida um debate para análise posterior, do currículo em ação. "BNCC e currículos têm papéis complementares para assegurar as aprendizagens essenciais definidas para cada etapa da 
Educação Básica, uma vez que tais aprendizagens só se materializam mediante o conjunto de decisões que caracterizam o currículo em ação" (BRASIL, 2017, p.18).

Além disso, a BNCC afirma que os conteúdos devem ser considerados na organização de currículos levando em consideração propostas adequadas às diferentes modalidades de ensino e realidades as quais a instituições estão inseridas e isso foi reconhecido na seguinte US.

[...] você tem que reformular sua forma de ver e pensar no ensino noturno, não adianta você chegar aqui e digamos assim, despejar conteúdos que dessa forma não funciona, então você tem que rever sua forma de pensar e adequar a nova realidade que você está vivendo. (2012 $\mathrm{ENEQ}^{02}$ - grifo nosso)

$\mathrm{Na}$ construção do currículo é preciso considerar que este documento deve direcionar, de acordo com a BNCC, para "aprendizagens sintonizadas com as necessidades, as possibilidades e os interesses dos estudantes e, também, com os desafios da sociedade contemporânea" (BRASIL, 2017, p. 14), sendo assim, é preciso propor um currículo preocupado com os interesses dos Estudantes, havendo assim, uma possibilidade de que o processo de ensino aprendizagem apresente uma melhora. Ainda, ao assumir-se um currículo há uma defesa de uma determinada ideia, seja de mundo, de escola, de aluno, de aprendizagem, de Ciência, etc. Conforme apontam as seguintes US.

A través de los trabajos mencionados se reconoce la necesidad de diseñar un currículo con el que se logre captar el interés de los estudiantes y desarrollar actitudes favorables para el processo de enseñanza aprendizaje considerando la estructura. (portal $\mathrm{CAPES}^{\text {04( espanhol) }}$ - grifo nosso)

Quando a gente faz o currículo a gente se posiciona, assume uma visão de sociedade, uma visão de escola, uma visão de aluno, uma visão de mudo que vai defender, e por isso vai propor o currículo dessa e dessa forma. (portal $\mathrm{CAPES}^{01}$ - grifos nossos).

Conclui-se essa categoria, afirmando que algumas pesquisas voltadas ao currículo, têm apresentado uma preocupação em propor metodologias alternativas ao tradicional, com o objetivo de alcançar-se uma melhora do processo de ensino-aprendizagem nas escolas Brasileiras. Em tese, estão claros os pressupostos, embora ainda se tenha pouco explícito sobre quais critérios teóricos é possível faze-lo, incluindo esses debates para além de situa-los apenas no campo de alternativas metodológicas. Ou seja, organização curricular é mais que definir método de ensino e aprendizagem.

\section{CONCLUSÕES}

É notório que nos últimos anos teve-se um bom número de publicações voltadas ao currículo de química, porém, percebe-se que são poucas as pesquisas preocupadas em explicar em quais critérios baseiam-se os professores para a escolha de suas ações curriculares e/ou dos conteúdos relevantes para compor tal currículo. Percebe-se a partir das categorias, que os pressupostos curriculares estão sendo mais debatidos que as práticas pautadas em tais pressupostos. E, também pouca relação destes, com outros campos do conhecimento a exemplo da epistemologia da ciência e, da psicologia da aprendizagem e desenvolvimento.

Dado o contexto em que muitas são as fragilidades apontadas na educação brasileira, e não é diferente na Educação Química, é necessário que exista uma preocupação também, com as formas de operacionalizar um currículo que esteja mais próximo da vida dos estudantes e por consequência da sua aprendizagem. O conhecimento escolar contextualizado é de outra natureza que o distingue do 
conhecimento científico descontextualizado. As publicações apresentam metodologias como meios de auxiliar o trabalho docente nessa compressão, sempre argumentando da aproximação dos conhecimentos científicos com os conhecimentos presentes nos cotidianos. Contudo, ainda relata-se muito pouco acerca de como de fato essa relação se dá nas aulas de Química com fundamentos da epistemologia das ciências, da psicologia, antropologia, etc.

Evidencia-se também, que há a percepção claramente argumentada de que a construção de um currículo com a visão CTS e/ou outros temas vivenciais vêm fazer a aproximação desejada dos conhecimentos científicos com a formação de um cidadão crítico, capaz de perceber uma visão social da ciência na construção da sociedade na qual estamos inseridos. Mas também se pode avançar no debate sobre como se desenvolve a habilidade do pensamento crítico e deliberativo. Entende-se que as ferramentas teóricas, utilizando-se da linguagem científico-escolar, torna-se o meio essencial, para desenvolver o pensamento crítico e analítico, que tanto se almeja como concepção.

Nessa relação, evidenciada nas categorias emergentes, percebeu-se que há uma preocupação dos pesquisadores em ensino de Química em propor alternativas metodológicas às abordagens tradicionais de ensino, considerando ainda que é imprescindível conhecer a história do currículo, para que possamos entender que este importante documento evoluiu e que é fruto de um longo trabalho docente. Assim, conhecer a história e compreender as flexibilidades do currículo permite avança-lo de sua perspectiva clássica para uma perspectiva mais inovadora.

Enfim, a partir desse estudo, pretende-se avançar nessa análise acerca das práticas curriculares dos professores de química inseridos nas escolas, ou seja, interpretar o currículo em ação. Encerra-se, agradecendo-se a Coordenação de Aperfeiçoamento de Pessoal de Ensino Superior (CAPES) pelo financiamento da presente pesquisa.

\section{REFERÊNCIAS}

BARBERÁ, O.; VALDÉS, P. El trabajo práctico en la enseñanza de las ciencias: una revisión. Enseñanza de las Ciencias, v. 4, n. 3, p.365-379, 1996.

BRASIL, Parecer n. 15/98, de 1 de junho de 1998. Diretrizes Curriculares Nacionais para o Ensino Médio. Brasília, DF, 1998.

Lei de Diretrizes e Bases Lei $\mathbf{n}^{\mathbf{0}}$ 9.394. Disponível em:<http://portal.mec.gov.br/seed/arquivos/pdf/tvescola/leis/lein9394.pdf>, 1996.

Orientações Educacionais Complementares aos Parâmetros Curriculares Nacionais $(\mathrm{PCN}+)$. Ciências da Natureza e Matemática e suas tecnologias. Brasília: MEC, 2006.

- Ministério da Educação. Secretaria da Educação Básica. Fundamentos pedagógicos e estrutura geral da BNCC. Brasília, DF, 2017.

CHEVALLARD, Yves. La transposition didactique: du savoir savant au savoir enseigné. Paris: La Pensee Sauvage, 1991.

DELIZOICOV, D. Metodologia do ensino de ciências. São Paulo: Cortez, 1990 
DELIZOICOV, D.; ANGOTTI, J.A.; PERNAMBUCO, M.C.A. Ensino de Ciências: Fundamentos e Métodos. São Paulo: Cortez, 2002.

FILHO, P. F. Dos S. Uma Disciplina Teórica de Química para os alunos ingressantes no Curso de Graduação em Química. In: Revista Química Nova, Vol. 23, No. 5, 2000.

FONSECA, J. J. S. Metodologia da pesquisa científica. Fortaleza: UEC, 2002.

GALVÃO T.F., PEREIRA M.G. Revisões sistemáticas da literatura: passos para sua elaboração. Epidemiol Serv Saúde. 2014.

MELLO, Guiomar Namo de. Currículo da Educação Básica no Brasil: Concepções e políticas. [online] Disponível em <http://www.observatoriodopne.org.br/metas-pne/15formacao-professores/saiba-mais/curriculo-da-educacao-basica-no-brasil-concepcoes-epoliticas >, 2017.

MENEZES, Ebenezer Takuno de; SANTOS, Thais Helena dos. Verbete transposição didática. Dicionário Interativo da Educação Brasileira - Educabrasil. São Paulo: Midiamix, 2001. Disponível em: <http://www.educabrasil.com.br/transposicaodidatica/>. Acesso em: 09 de mar. 2018.

MORAES, Roque; GALIAZZI, Maria do Carmo. Análise Textual Discursiva. $2^{\text {a }}$ Ed. Revisada, Ijuí: Editora Unijuí, 2011.

MOTA, C. R.; VELOSO, N.; BARBOSA, S. Currículo para além das grades construindo uma escola em sintonia com o seu tempo. Salto para o Futuro. 2004.

PEREIRA, Maria Myrella. Currículo de Química: prescritividade versus planejamento anual. Trabalho de Conclusão de Curso (Graduação em Química) Centro de Ciências e Tecnologia, Universidade Estadual da Paraíba. Campina Grande $\mathrm{PB}, 2014$.

RITTER, Jaqueline. Recontextualização de políticas públicas em práticas educacionais: Novos sentidos para a formação de competências básicas. Curitiba: Editora Appris, 2017.

SACRISTÁN, J. G. El curriculum: una reflexión sobre la práctica. Madrid: Ed. Morata, 1995.

SANTOS, W. L. P. O Ensino de Química para formar o cidadão: principais características e condições para a sua implantação na Escola secundária brasileira. Dissertação. Campinas: Faculdade de Educação/UNICAMP, 1992.

SANTOS, W. L. P.; MORTIMER, E. F. Uma análise de pressupostos teóricos da abordagem CTS (Ciência-Tecnologia-Sociedade) no contexto da educação brasileira. In Revista Ensaio. Belo Horizonte, v.2, n.2, 2000. p. 133-162.

SANTOS, Wildson Luiz Pereira dos. Significados da educação Científica com enfoque CTS. In: SANTOS, Wildson Luiz Pereira dos; AULER, Décio (orgs.). CTS e educação científica: desafios, tendências e resultados das pesquisas. $1^{\mathrm{a}}$ Ed., Brasília: Editora da Universidade de Brasília, 2011. (p.21 - 42). 
SANTOS, Wildson Luiz Pereira dos; AULER, Décio (orgs.). CTS e educação científica: desafios, tendências e resultados das pesquisas. $1^{\mathrm{a}}$ Ed., Brasília: Editora da Universidade de Brasília, 2011.

SILVA, Tomaz Tadeu da. Documentos de Identidade: Uma Introdução às Teorias de Currículo. $3^{\text {a }}$ Ed., Belo Horizonte: Editora Autêntica. 2009.

TABA, Hilda. 1962. Curriculum development: Theory and practice. New York: Harcourt, Brace \& World, 1962.

TYLER, R. Basic principles of curriculum and instruction. Chicago: University of Chicago Press, 1968. 